\title{
Representaciones sobre éxito y discriminación de mujeres ejecutivas en Brasil*
}

Delfino, Andrea**

\section{Resumen}

El objetivo principal de este artículo es reconstruir las representaciones sobre la discriminación y el éxito construidas por un grupo de mujeres ejecutivas de empresas de gran porte en la ciudad de Río de Janeiro, Brasil. Teniendo como base los relatos de once mujeres ejecutivas. Efectuando la reconstrucción de las representaciones mediante el empleo de la técnica de análisis del discurso. Fue posible observar que a pesar de no ser completamente homogéneas, las representaciones sobre el éxito y el logro translucen prácticas que tienden a distanciarse de los criterios dominantes y expanden dentro del grupo estudiado valores diferentes a la jerarquía, al utilitarismo y a la competencia. Sin embargo, las representaciones y las prácticas innovadoras en este aspecto conviven con representaciones de la discriminación que actúan minimizando la existencia de las desventajas de género. Este tipo de representaciones estaría dando cuenta del surgimiento de un nuevo tipo de trayectoria profesional femenina, la cual sin embargo no contiene la perspectiva de una acción política mayor que pueda potenciar la situación de cambio y hacerla extensiva a otros segmentos ocupacionales.

Palabras clave: Representaciones, éxito, discriminación, mujeres ejecutivas.

\section{Representations of success and discrimination against women executives in Brazil}

\section{Abstract}

The principal objective of this study is to reconstruct the representations of discrimination and success presented by a group of women executives in imprtant companies in Rio de Janeiro, Brazil.

\section{Recibido: 04-08-04. Aceptado: 04-11-15}

* Este artículo fue elaborado con base en la tesis de maestría "Mulheres e Executivas: trajetórias de gênero no Brasil", 1999, PPGSA - IFCS - Universidade Federal do Rio de Janeiro. Directora: Prof. Alice Rangel de Paiva Abreu.

** Licenciada en Ciencia Política. Magister en Sociología y Antropología - Universidade Federal do Río de Janeiro - Brasil y Profesora de la Facultad de Ciencia Política y Relaciones Internacionales Universidad Nacional de Rosario - Argentina. E-mail: andelfino@yahoo.com.ar 
The study is based on the experiences of eleven women executives. The reconstruction of the representations were undertaken through the use of the discouse analysis technique. It was possible to observe that even though they were not completely homogeneous, the representations of success indicate practices that tend to deviate from the dominant criteria, and expand in different value areas such as hierarchy, utilitarianism, and competence. However, the representations and innovative practices in this aspect co-exist along with representations of the discrimination that acts to minimize the existence of gender disadvantages. This type of representation gives evidence of an upsurge in a new type of feminine professional career, which still does not contain the perspective of greater political action which could empower the situation of change and make it more extensive to other occupational segments.

Key words: Representations, success, discrimination, women executives.

\section{Introducción}

La duplicación del número de mujeres ocupando puestos directivos en empresas brasileñas entre 1996 y $1997^{1}$ se registra en un contexto históricamente nuevo, caracterizado fundamentalmente por los altos niveles de escolaridad femenina y por una incorporación masiva y más permanente de las mujeres en el mercado de trabajo. A estos elementos, que caracterizan una primera etapa de la construcción de un nuevo tipo de trayectoria profesional femenina, es posible sumarle un tercer aspecto relacionado con la difusión de métodos anticonceptivos eficaces que actúan permitiendo un mayor control de las biografías (Bozon, 1995). Así, la evolución del estatuto femenino, caracterizada por algunos signos de cambio, demandará la negociación de nuevas relaciones sociales en un contexto histórico reformulado.
Aunque estos comportamientos presenten evoluciones muy nítidas, sus efectos no van sólo en una dirección. Junto a estos claros elementos de progreso y modernidad permanece una división sexual del trabajo entre hombres y mujeres enraizada en representaciones tradicionales que contienen como elemento central un fuerte componente afectivo. La permanencia de desventajas relativas a las condiciones de trabajo y salario diferenciales, la segregación ocupacional horizontal y el ingreso minoritario de las mujeres en cargos ejecutivos (segregación vertical) son ejemplos claros de la permanencia de este tipo de estructuras. Así, es importante destacar que, si bien desde los últimos años de la década del 90 el número de mujeres ejecutivas en Brasil ha crecido, ellas representaban hacia 1997 sólo el 17,3\% de la cantidad total de cargos gerenciales y administrativos según datos de las Naciones Unidas (InfoPYME, 2001).

1 Estos datos fueron obtenidos por el periódico Folha de São Paulo en una investigación hecha en empresas de consultoría especializadas en seleccionar ejecutivos (Folha de São Paulo, 25 de enero de 1998). 
Esta situación compleja y, por momentos, contradictoria, constituye el marco dentro del cual intentaremos reconstruir las representaciones que sobre la discriminación y el éxito construyen un grupo de once mujeres ejecutivas de empresas de gran porte de la ciudad de Río de Janeiro, Brasil.

Teniendo como base los relatos de once mujeres ejecutivas (tres de esos relatos pertenecen a mujeres de la faja etárea mayor a 40 años) la reconstrucción de las representaciones fue realizada a través de la técnica del análisis del discurso y mediante el procedimiento de la codificación básica²

En las representaciones se encuentran categorías de clasificación, imágenes, símbolos que organizan las relaciones de los individuos con la naturaleza, así como las relaciones de los individuos entre sí. Para Michel Bozon (1995), las representaciones designan las camadas de realidades más antiguas, pero también las más estables y las más implícitas de la visión del mundo de los individuos. Esta visión del mundo se presenta con frecuencia como natural, sin exigir ninguna justificación. Las representaciones organizan la percepción, pero se pueden objetivar en instituciones $u$ objetos. Las prácticas, ya sean individuales o colectivas, son comportamientos realizados y pueden revelar la persistencia de representaciones que se vuelven inconscientes.

Por conjugar en su interior la permanencia y el cambio, las representacio- nes sobre la discriminación y el éxito nos brindarán un fructífero camino para reflexionar sobre la transformación o reproducción de los roles de género, así como la permanencia de la subordinación o la apertura de una perspectiva de emancipación.

\section{El contexto socio histórico}

Las trayectorias profesionales de las mujeres ejecutivas constituyen casos atípicos, a la vez que se desenvuelven en un espacio histórico-social único y diferente, caracterizado por algunos signos de cambio. En este sentido, Andréia Puppin (1994) señala que como integrantes de las clases medias favorecidas, este grupo de mujeres, tuvo la posibilidad de minimizar sus desventajas de género en una coyuntura histórica abierta a la superación relativa de ese orden de clivajes.

Esta situación atípica y favorable se desprende en los relatos de sus historias de vida profesional: "Yo comencé a trabajar, hace que me gradué como psicóloga, ... yo me gradué en el $96 \ldots$ no, en el 95 como psicóloga y en el 94 como bachiller, entonces, de graduada efectivamente yo tengo 3, va a hacer 4 años, ¿no es? Es poco tiempo para... yo siempre, así,... con excepción de mi primer empleo que no tenía un cargo de jefatura los otros dos empleos que yo tuve ya fueron cargos de jefatura. Suerte y competencia, porque sino yo no habría sido recomendada. Yo tengo 25 años, cuando me gradué yo tenía 22, estaba por cumplir 23, y 
no es una cosa muy... por lo que yo observo, no es una cosa muy común... ¿no es? Entonces, yo me considero una persona, así, que tuvo muchas buenas oportunidades de trabajo para estar donde estoy."

"Quiero decir, mi ida para allá fue una cosa así... que rompió de a poco con los patrones de lo que era esperado de una empresa industrial en Brasil, ¿no es?"

"Entonces, quiere decir que fui la primera mujer contratada para trabajar en N.N., como trainee, para hacer un curso en el área financiera llamado Internacional Trainee Program. Eso fue en 1973. Yo tenía 22 años."

Este tipo de prácticas laborales se encuentran atravesadas por signos de cambio a nivel social, pero estos cambios en algunos aspectos son muy débiles y sólo pueden ser reconocidos por las ambigüedades que crean o reproducen. Ellos pueden ser interpretados como formando parte de la asimilación -aunque parcial- por parte de los sectores medios urbanos latino-americanos de una serie de fenómenos denominados por los demógrafos europeos de "segunda transición demográfica" (Kaa, 1987). Ese término, va a ser utilizado para describir el nuevo desequilibrio demográfico -posterior a una situación de equilibrio- caracterizado por: (a) la declinación del casamiento como institución; (b) la caída de la tasa de fecundidad por debajo del nivel de reproducción de una generación; y (c) el surgimiento de un nuevo acuerdo familiar, caracterizado por el aumento de fa- milias monoparentales. En el marco de esta perspectiva, el nuevo desequilibrio seria producto de una reivindicación de derechos individuales ${ }^{3}$.

Según Bozon (1995), seria necesario incorporar, a este análisis, un cuarto elemento: las mudanzas en las relaciones de género, sustentadas en una mayor autonomía femenina. Tres son los elementos que marcan este cambio: (a) el aumento del nivel de instrucción femenina (que llega a superar los niveles masculinos); (b) la participación más elevada y más permanente de las mujeres en el mercado de trabajo; y (c) la difusión casi generalizada de los métodos anticonceptivos eficaces, que permiten una conquista por parte de las mujeres, del dominio de su fecundidad $y$, junto con eso, del control de su biografía. Todos estos cambios están exclusivamente referidos a las mujeres.

En Brasil estas transformaciones están claramente presentes en los patrones de comportamiento de las mujeres de los sectores medios urbanos. Así, es posible observar que dentro de la población con grado superior completo las mujeres representaban el $25,5 \%$ en 1970 y pasan a representar el $44,6 \%$ y el $51 \%$ en las décadas de 1980 y 1990 respectivamente. Respecto a la tasa de fecundidad, ésta muestra una notable caída pasando de 6,2 en 1940 a 2,6 y 2,1 en 1990 y 2000 . Es importante destacar que estas últimas cifras esconden en su interior profundas heterogeneidades, sin embargo lejos mi- 
nimizar el análisis actúan reforzándolo. Según datos del IBGE el censo de 2000 mostraba que las brasileñas de mayor renta tenían en promedio 1,11 hijos; en el extremo opuesto la tasa de fecundidad de las mujeres de menor renta era de 5,3 hijos por mujeres.

\section{Las desventajas de género: obstáculos y salidas}

En este punto analizaremos, a partir de los relatos obtenidos de las mujeres ejecutivas de la ciudad de Río de Janeiro, las características centrales de las representaciones sobre la discriminación de género en el mundo del trabajo. Es decir, intentaremos desmenuzar los elementos centrales que caracterizan la mirada de las mujeres ejecutivas sobre las distinciones, exclusiones o restricciones laborales basadas en el sexo.

Adicionalmente relevaremos la opinión de este grupo de mujeres respecto de la implementación de las denominadas políticas de acción afirmativas. Sin embargo, por exceder los objetivos de este artículo y por corresponder a un ámbito disciplinar diferente a la sociología -campo en el que se inscribe este artículo- no serán abordadas las normativas jurídicas existentes tendientes a intervenir en las inequidades de género en el ámbito laboral.

\subsection{Los obstáculos}

La percepción de la discriminación en el espacio laboral, en los relatos de las mujeres ejecutivas, adopta algunas características peculiares. En la mayor parte de los relatos es presentada como una situación no vivenciada a nivel personal y que camina junto con la idea de que los progresos en la carrera son consecuencia exclusiva de la "competencia profesional", aliados al éxito de algunos tipos de estrategias individuales como la de la negociación.

En este caso específico, la noción de "competencia profesional" esta referida a una capacidad técnica, a una calificación profesional adquirida en el ámbito educativo y laboral y no a una cualidad personal o profesional indicativa de un modo de ser, de una aptitud y/o de una característica personal.

Como señalábamos anteriormente, los progresos en la carrera basados en la "competencia profesional" se conjugan, en los relatos, con estrategias ancladas en una red de relaciones informales, nombradas como "habilidad política" o "capacidad de articulación política". Este tipo de estrategia ya fue visualizada, para el contexto brasileño, por Santos (1982) en una investigación que tenía por objetivo el análisis de las trayectorias profesionales de mujeres universitarias en empresas estatales. Allí, la autora sugiere que este tipo de prácticas actúan como una forma en extremo individualista de contornear barreras discriminatorias. En una investigación desarrollada dos décadas después por Merriel-Sandes y Kolb (2001) las autoras vuelven a focalizar nuevamente en la aparente necesidad de las mujeres de invertir en la construcción de relaciones con personas que ejerzan una influencia protectora con el objetivo de apoyarlas hacia posiciones de liderazgo y hacer de las capacidades de liderazgo femeninas visibles y explícitas a los otros: "Yo no concuerdo con eso [que las mujeres deben trabajar más que los hom- 
bres para demostrar sus capacidades y sus resultados]. Yo no tuve esa experiencia. En mis cinco años de profesión, incluso cuando era pasante, yo no tuve esa experiencia. Yo creo que no es la cantidad de tu trabajo, es la calidad de tu trabajo, cómo uno muestra eso para las personas. No, yo no concuerdo."

"Mirá, en mi experiencia yo no vi que eso acontezca [que las mujeres progresen más lentamente que los hombres en el interior de la jerarquía de la empresa]. Las oportunidades... incluso porque mi área es un área que habla de las oportunidades de las personas dentro de las empresas. Yo trabajé en tres empresas, con ésta en la que estoy hoy, en ninguna de ellas yo sufrí discriminación... era sólo por la competencia."

"En el nivel que yo llegué hoy, cualquier progreso a un cargo mayor es meramente político. Es nuestra capacidad de articulación política, de relaciones dentro de la empresa y fuera. Hasta aquí la relación,... la calificación es técnica, meramente técnica, no quiere decir que nuestras habilidades políticas no cuenten. Pero de aquí en adelante no cuenta eso, es la habilidad política, de interrelación. No siempre va a prevalecer la competencia profesional."

Cuando es vivenciada, la discriminación es reformulada en la memoria adquiriendo características positivas:

" $Y$ ahí me testeaban mucho, mis propios colegas me testeaban mucho. Pero yo fui muy bien recibida. Era una empresa extremamente machista....quiero decir, desde el punto de vista de la relación de ellos con la mujer que trabajaba era una relación con la secretaria, allá en la fábrica no había mujeres ingenieras.
Entonces, son actividades que deben ser muy bien administradas. Ahora, había mucho más prejuicio del lado de mis colegas, que del lado de mis jefes... ¿no es? Mis colegas me testeaban mucho. Ellos querían saber si yo competía en igualdad de condiciones con ellos, si yo, por ejemplo, era capaz de hacer inventario físico, si yo trabajaba hasta media noche, todas esas cosas, ¿no es? $Y$ yo hacia eso,... ¿sabés? con la máxima tranquilidad, es decir, la única preocupación que yo tenía era... yo no tenía que hacer nada más allá. Yo no tengo que tener condiciones privilegiadas, ni tener que ser penalizada por el hecho de ser mujer. Yo tuve una muy buena receptividad, pero había mucha competencia conmigo. Yo tuve... yo siempre fui muy aplicada, estudiosa... aquellas cosas... sacaba buenas notas. Ellos me preguntaban: qué notas te sacaste? (...). Pero fue así, dos años y medio, trabajé prácticamente tres años en N.N. y fue así, un aprendizaje enorme."

Otra característica es que las desventajas de género son presentadas como un resquicio del pasado, casi disipadas por la "evolución natural" de las generaciones y pasibles de desaparecer por completo con el tiempo.

En esta idea subyacen las nociones de modernización y de progreso evolutivo entendidos como fenómenos que conllevan de forma intrínseca transformaciones positivas en la vida social, aumento de significado y alcance de la experiencia humana, así como también de la acumulación de adquisiciones materiales. En el punto siguiente volveremos sobre la positividad intrínseca del devenir histórico modernizante presente en los relatos: 
"Esto es así hasta cierto punto [que las mujeres deben trabajar más que los hombres para demostrar sus capacidades y sus resultados]. Pero creo que eso no es la realidad de hoy. Eso ya cambió mucho. Creo que la mujer tenía que probar que era capaz, hoy yo creo que ya no es así. Hasta por aquellas mujeres que llegaron hasta allá, el reconocimiento para las otras generaciones que vinieron, es natural. Pero yo creo que eso de la discriminación era, aquello que te comenté, te mandaban a hacer inventario físico, trabajar hasta las 3:00 hs. de la mañana. Pero yo creo que hoy... hoy el tratamiento es extremamente igualitario. Hay muchas mujeres en el área financiera y no existe, no hay diferencia de trato hombre/mujer, y los hombres no tienen problema con las mujeres, porque ellos también tienen mujeres que trabajan. Esto significa que se produjo algún cambio..."

"Yo creo que eso no es así hoy [que las mujeres progresan más lentamente que los hombres en el interior de la jerarquía de la empresa]. Creo que hoy el nivel de oportunidad es el mismo. Creo que eso no tiende a ser verdad. Yo creo que hoy existen varias mujeres alcanzando cargos, es decir... de nivel con menor edad que los hombres. Yo creo que no es más verdad, aunque sí fue verdad en otra época. Yo creo que no es más verdad de aquí en adelante, que estamos viviendo en la década del 90."

Finalmente, la discriminación de género en el ámbito laboral tiene una existencia teórica, pero prácticamente sin relevancia en la vida práctica e individual de las mujeres ejecutivas entrevistadas. Es decir, en los relatos la discriminación de género en el mundo del trabajo está presente como concepto, como una idea racionalmente elaborada mas que como una experiencia vivenciada en algún momento o momentos de su trayectoria laboral:

"Mirá, en mi área que es recursos humanos, sí, es un poco diferente [que las oportunidades de trabajo son diferenciales para los hombres que para las mujeres]. Porque generalmente quien dirige recursos humanos es un hombre y dirige mujeres... ¿no es? Que son psicólogas, por ejemplo. Generalmente son administradores de empresa, entonces, ellos colocan una persona, una mujer joven en un cargo de dirección y psicóloga, él ya tiene.....un poco de estereotipo, el salario es diferenciado... ¿no es? En empresas mayores que la que yo trabajo hoy, existe todavía esa diferenciación salarial porque generalmente quienes contratan son hombres. Yo creo que la mujer independientemente del área de ella, pero yo hablo por mi área, el hecho de ser mujer hace que tenga que mostrar los resultados mucho mas palpables... ¿no es?"

\subsection{Los caminos de salida}

El concepto de acciones afirmativas se refiere a las estrategias políticas volcadas a intervenir sobre la asimetría entre los sexos en diferentes instancias de la vida pública, especialmente en la política y en el mercado de trabajo.

En el universo del trabajo, la concepción que fundamenta el proyecto de superación de la inferioridad de la mujer, exige una acción conjunta de responsabilidades innovadoras en el dominio jurídico/legal, de medidas de orientación internas al ejercicio del trabajo y de políticas 
específicas para neutralizar o superar los obstáculos y los condicionamientos de las prácticas de desigualdad. En este sentido, las acciones afirmativas tienen por objetivo contribuir a cancelar o corregir las desigualdades de hecho, de manera de promover la presencia y la participación de las mujeres en todos los sectores profesionales y en todos los niveles de responsabilidades (Cappellin, 1996).

Según Laufer (1986), las acciones positivas pueden ser definidas como las estrategias direccionadas a combatir no solamente las discriminaciones directas, las cuales son intencionales y apuntan directamente a las mujeres, sino también las discriminaciones indirectas que son consecuencia de la división sexual del trabajo y de roles en los diferentes planos de la organización del trabajo.

En este sentido, es posible distinguir dos tipos de acciones positivas. Por un lado aquellas direccionadas a corregir las prácticas de empleo implícitamente discriminatorias con relación a las mujeres y que son el objetivo esencial de la realización de la igualdad de trato. Se refiere a la forma de actuar sobre los procesos y, especialmente, sobre las prácticas de todas las etapas de la vida profesional (reclutamiento, evaluación, promoción, etc.) que conducen a un tratamiento desigual hacia las mujeres. Por otro lado, aquellas orientadas a promover la igualdad de oportunidades, adoptando medi- das temporarias tomadas en beneficio de las mujeres. Tales acciones son tomadas como paliativos del atraso histórico acumulado en tal o cual sector y/o empresa por las mujeres.

Tres son las cuestiones centrales para comprender las finalidades de esas acciones y sus implicancias:

a. Las medidas de recuperación temporaria no deben encontrar su curso en una 'especificidad femenina', sino en una situación particular de desigualdad que las mujeres enfrentan en el trabajo asalariado. Esas medidas no deben ser confundidas con una perspectiva tradicional de protección de las mujeres en el mercado de trabajo.

b. Otra característica de estas medidas es su dimensión colectiva. No se trata de tomar medidas por una mujer en el trabajo, sino por un grupo de mujeres situadas en relación a un oficio o a una empresa. Son medidas concretas que no pueden ser uniformes, sino adaptadas a la diversidad de situaciones.

c. Finalmente, es preciso señalar que la mayoría de las acciones positivas tuvieron por objetivo posibilitar la igualdad de oportunidades en el plano profesional recorrido sólo por las mujeres. A este enfoque podremos contraponer otro, basado en las medidas tomadas para con los dos sexos, un enfoque más propicio a la realización de la mixidad ${ }^{4}$ de los empleos, condición

4 El neologismo mixidad fue utilizado para traducir el termino mixité. Los términos franceses mixte y mixtion hacen referencia a aquello que resulta de la mezcla de dos o más cosas o sustancias. Derivada de esa significación, la noción de mixidad social refiere a una de las modalidades de las relaciones sociales de sexo, en tanto supone la coexistencia de hombres y mujeres en un espacio social común. 
de una verdadera igualdad profesional.

La implementación de acciones afirmativas en el contexto empresarial constituye, a partir del sostenimiento de una gestión diferenciada de la mano de obra masculina y femenina, una dinámica de modificaciones en relación a la división sexual del trabajo. Estas son pasibles de ser desdobladas en medidas de formación de personal (en términos de definición de porcentajes, por ejemplo); mecanismos de reorganización de los procesos de trabajo (como la reserva de empleo para mujeres en aquellos puestos que rompan esquemas tradicionales de división sexual del trabajo); medidas de reclutamiento (como en el caso del establecimiento de la mixidad efectiva respecto de la contratación para funciones anteriormente masculinizadas); medidas de promoción (como la puesta en práctica de políticas de promoción preferencial para las mujeres que no disfrutaron de estos mecanismos en los últimos años) y medidas de remuneración del personal (como la equiparación monetaria a las mujeres de nivel de formación y experiencia equivalente al de los hombres, pero que continúan recibiendo una de remuneración inferior) (Puppin, 1998).

No obstante la importante adhesión que este tipo de políticas tiene en los países desarrollados y en algunas expresiones del movimiento feminista, al interior de los relatos de las mujeres ejecutivas brasileñas es posible observar un claro rechazo a este tipo de políticas. Resultados similares surgieron de una investigación realizada por Lidia Heller (2002, 2003) con ejecutivas argentinas. Para la autora, las ejecutivas argentinas (a dife- rencia de las europeas o americanas) rechazan con fuerza cualquier iniciativa de igualdad de oportunidades, a pesar que serían estos programas impulsados a través de políticas públicas o empresariales los que pueden favorecerlas.

En este sentido, los relatos de las ejecutivas brasileñas se construyen en torno al par de opuestos: política/naturaleza. Dentro del par, las políticas activas en materia de igualdad de oportunidades son colocadas del lado negativo del par, contraponiéndose a la positividad intrínseca de un devenir histórico modernizante:

"Eso debe ser un proceso natural. Yo creo que en los Estados Unidos, por ejemplo, es posible ver una situación de esas que la protección de las minorías tiene que ser de no sé cuantas mujeres. Yo creo que la vida de la mujer americana no es mejor que la vida de la mujer brasileña. (...) esa imposición de la sociedad. Yo creo que es una cuestión natural."

Las ideas de progreso y modernización presente, fundamentalmente, en los relatos de las ejecutivas de la faja étarea mayor de 40 años se encuentran fuertemente emparentadas con la matriz funcionalista propia de la sociología americana de las décadas del 50 y 60 . Dentro de esta tradición de pensamiento el progreso es evolutivo e involucra cuatro etapas: diferenciación, inclusión, adaptación paulatina o gradual y generalización de valores.

Con la modernización se produce una clara diferenciación entre sociedad y personalidad, relacionada con una creciente autonomía personal. Este proceso es acompañado por una paulatina inclusión de todos los miembros relevantes 
para el funcionamiento general de la sociedad que anteriormente habían estado excluidos. Así, la inclusión es producto del desarrollo de capacidades que contribuyen al funcionamiento de la sociedad. Hacia la década del ' 60 incorporación de las mujeres de clase media al mercado de trabajo representa para el funcionalismo un nuevo paso en el proceso de inclusión. Es a partir de la creciente eficacia y eficiencia del funcionamiento de estas dos etapas que se produce la adaptación gradual y paulatina a la nueva situación.

Para García de Fanelli (1991), el optimismo de los años '60 respecto de las posibilidades de desarrollo económico, industrialización y democratización en América Latina se reflejó también en una interpretación positiva del incremento de la participación femenina. En este sentido la incorporación de las mujeres al mercado de trabajo remunerado era considerada de por sí como un signo más del proceso de modernización.

Sin embargo, en el grupo de ejecutivas más jóvenes esta interpretación modernizante convive, de forma paradójica, con su opuesto. Es decir, convive con un discurso que otorga a la crisis económica y a la caída de los ingresos familiares un lugar significativo en el proceso de incorporación femenina al mercado de trabajo:

"Yo creo que ese cambio dependió básicamente de una necesidad económico-financiera. Que las mujeres tuvieron que trabajar, no se pudieron dar más el lujo de quedarse en casa, ¿no es? Quiero decir, existía aquel deseo de trabajar, muchas recorrieron ese camino que fue muy largo, principalmente para mi generación, de llegar hasta allá. Y para las generaciones subsiguientes fue más por la necesidad... de tener que trabajar... hombres y mujeres tienen que trabajar, con raras excepciones. Entonces, naturalmente van conquistando espacios."

Sintéticamente, los relatos de las mujeres ejecutivas brasileñas respecto de las políticas de acciones afirmativas permiten observar: a) la permanencia, hacia fines del siglo XX, de discursos y de representaciones que otorgaban a la incorporación de las mujeres al mercado de trabajo un carácter modernizante, $y$ b) inexistencia de un consenso social profundo que pueda traducirse en la perspectiva de una acción política que promueva y potencie las transformaciones en el rol femenino dentro del campo laboral.

\section{Más allá de los cinco minutos de fama}

Los análisis sociológicos que interpretaron la relación de las mujeres con el éxito ha permanecido, desde las décadas del 60 y 70, muy próximas de categorías psicológicas, tales como "temor al éxito" (Reygadas, 1998), "miedo al fracaso", "evitación del éxito" (Markus, 1990) y otras similares. Categorías éstas, que hacían referencia a la opción de no enfrentar situaciones de competencia, en la empresa, con otros hombres; por aspirar más por el progreso de su cónyuge que por el propio y, finalmente, por percibir como un riesgo la negociación entre el éxito profesional y el equilibro familiar y afectivo. Para Puppin (1998), serían las imágenes de éxito interiorizadas (que suponen la absorción de estereotipos masculinos) las que pondrían en riesgo la noción de feminidad definida socialmente 
en torno de las nociones de sacrificio de sí mismo, de dedicación a los otros de dependencia y vulnerabilidad.

Sin embargo, el contraste entre estas formas históricamente específicas de relativo "desinterés" femenino con las formas de éxito socialmente prescriptas y normativamente fijadas, nunca fueron pensadas como prácticas que llevan a una definición diferente del éxito por parte de las mujeres. En este sentido, Markus (1990) recuerda que a pesar de que su significado haya cambiado históricamente, el concepto de éxito siempre ha conllevado la convergencia de dos criterios como mínimo: su conexión con algún tipo de logro, y su dependencia para con el reconocimiento público. Por el contrario, sus alteraciones históricas no sólo conciernen a las formas concretas de éxito, sino también a sus dominios, sus sujetos, los beneficios sociales que acarrea 'tener éxito', junto con los cambios en los tipos y formas institucionales de lo público llamado a juzgar este éxito.

En las mujeres ejecutivas se puede apreciar un alto valor atribuido al trabajo como una fuente de independencia, de autonomía y de realización personal. Así, el trabajo aparece justificado desde una perspectiva que conjuga la posibilidad de mayor bienestar familiar con una perspectiva de desarrollo individual. La percepción del éxito está básicamente relacionada con su formación académica, manifestando una valoración muy positiva de sus capacidades profesionales, su inserción en el mercado de trabajo y sus capacidades personales. En este sentido, el éxito depende en gran parte del esfuerzo, de las capacidades y de las habilidades personales y se conjuga con estra- tegias centradas en el fortalecimiento de la auto-estima y en la ausencia de reconocimiento de los factores discriminatorios o desventajosos para las mujeres (Arango, 1998):

"De la misma forma como yo divido con él, mitad y mitad, matemáticamente calculado los gastos de la familia, porque nosotros tenemos auto. Yo viajé de vacaciones ahora, entonces, ....cada uno pagó sus vacaciones, cada uno llevó su dinero para gastar, porque sino es imposible tener un buen padrón de vida, ¿no es?"

"Yo creo que sí [que las mujeres invierten tanto como los hombres en sus vidas profesionales]. Las jóvenes que trabajan hoy, aquí, conmigo tienen tantas ansias de poder, de saber, de posesionarse, de conocer, de trabajar, de viajar, de aprender, igual que los hombres. No es... para mí, no es diferente. Yo creo más aún, creo que la mujer por el hecho de tener que mostrar que son tanto como ellos, ellas se preocupan más que los hombres. Ellas tiene una actitud mucho más productiva que los hombres."

Se pudo observar en las mujeres entrevistadas una perspectiva del éxito dada en términos de una auto-realización; es decir, una inclinación personal a desarrollar tareas placenteras que permiten el uso pleno de sus potencialidades y el desarrollo de la personalidad. Según Markus (1990), este tipo de formulación está relacionada a la experiencia del éxito como una "experiencia privada", relacionada con satisfacciones concretas en algún aspecto específico de la vida. En este caso particular el trabajo no engendra ningún reconocimiento externo, ni siquiera social (o mejor, el reconocimiento externo o social no se constituyen en su 
condición). Así, la calidad del trabajo y de los contactos interpersonales tienen una importancia mayor que el reconocimiento y las recompensas sociales o externas:

"Primero, a mí me gusta mucho trabajar con personas, eso es una cosa que me gratifica mucho en mi trabajo. Otra cosa que me gratifica mucho de mi trabajo es que yo me divierto mucho con mi trabajo, yo trabajo con placer, mi trabajo no es una carga. Fue una elección por placer que yo hice... ¿no es? una cosa de vocación. El me permite usar una cosa que ahora se está convirtiendo en moda, asunto de congresos internacionales, que es la intuición. Porque como nosotros trabajamos con personas y eso yo creo que es el gran diferencial de la mujer respecto del hombre, es la capacidad intuitiva, de usar la intuición que ella tiene, eso que nosotros decimos: "Vamos a profundizar, vamos a observar, pero yo creo que no es....". Hay alguna cosa interior tuya que 'habla', que es lo que yo llamo intuición. El hombre también tiene, yo creo que eso no es privilegio de las mujeres. El problema es que socialmente, culturalmente ellos aprendieron a no creer en eso y a no usar... ¿no es?, pero cada día que pasa yo tengo comprobaciones, así... concretas de que funciona. Esa es una cosa que en mi trabajo, yo puedo utilizar mucho porque yo trabajo directamente con personas y seleccionando y entrevistando y todas esas cosas, ..... veces yo converso con Cintia y digo así... mirá, yo no se lo que es pero vamos a tener algún problema. Entonces, esos son algunos de los elementos de mi trabajo que me dan mucho placer (...) Y la facilidad de estar (...) el acceso a la tecnología de punta. (...) Eso también es una cosa muy gratificante."

"Él [refiriéndose a su esposo] iba para São Paulo porque el no era de allá, el estaba en Amazonas porque es militar, entonces, iba ser transferido a São Paulo, pero en función del problema de salud que tenía, tuvo que volver para acá. Entonces yo renuncié... ¿no es? En la empresa todos se lamentaron. Entonces, ellos quisieron, todavía, quedarse conmigo como consultora, no quisieron colocar a nadie en mi lugar. Pero era una locura, porque yo me quedaba una semana en São Paulo, una semana en Río... una semana en São Paulo, una semana en Río y haciendo todo lo que yo hacía antes cuando estaba allá todos los días. Entonces, yo entraba a trabajar... cuando yo estaba trabajando allá todo el día normalmente, entraba a las ocho de la mañana, yo era quien abría el escritorio, y nosotros también teníamos una fábrica en Pindamonhangaba, yo gerenciaba la parte de recursos humanos de la fábrica, entonces, una vez por semana o cada quince día yo iba para la fábrica. Ellos quisieron permanecer de esa forma, entonces, cuando yo estaba trabajando normalmente yo entraba a las ocho de la mañana hasta las siete $u$ ocho de la noche... ¿no es? y cuando yo me quedé trabajando solamente como consultora para ellos dos veces por mes, cada quince día, toda la semana, yo trabajaba de ocho de la mañana hasta las diez de la noche, incluso había días que salía de allá a las once porque tenía que hacer todo lo que yo hacía antes... ¿no es? Entonces, yo llegaba allá y eran pilas de papel en mi mesa, las personas me llamaban por teléfono a Río. 
Yo soy muy exigente con la calidad de mi trabajo y creí que no estaba siendo productivo para mí, ni un buen resultado para la empresa. Me senté con el presidente de la empresa y le dije que no quería más, que ellos colocasen una persona, que la demanda de la empresa era muy grande y la calidad de mi trabajo estaba quedando comprometida......y eso es inadmisible... ¿no es? Así, yo recluté una persona y la coloqué allá y yo me quedé en Río."

La definición del éxito en término de una "experiencia personal interpretada como satisfacción" (Markus, 1990: 157) se opone a los criterios externos de éxito ligados a los modelos guerreros de vencedor ${ }^{5}$, y visualizados en la importancia atribuida al ascenso a los niveles jerárquicos superiores de las empresas.

Este tipo de relatos presentan dos características principales. La primera de ellas es que no puede ser separado del tipo de trabajo realizado, en la medida que encuentra una fuerza mayor en los relatos de las ejecutivas del área de recursos humanos. La segunda característica es que está presente con mayor frecuencia entre las entrevistadas más jóvenes.

Es sumamente importante poder conjugar esta interpretación del éxito con la mirada que Pierre Boudieu (2000) reali- za de la idea de "intuición". Partiendo de un rastreo de pesquisas empíricas que dieron cuenta de la mayor sensibilidad femenina a los indicios no verbales, el autor concluye que la denominada intuición femenina constituye una "forma especial de peculiar lucidez de los dominados" (2000: 46). En este sentido sería inseparable del análisis de la sumisión objetiva y subjetiva que estimula u obliga a la atención y a las atenciones, a la vigilancia y a la atención necesarias para adelantarse a los deseos o presentir los disgustos.

Si bien la perspectiva de Markus aportaba novedosas líneas argumentales a la comprensión de una noción de éxito que se aparta de patrones tradicionales, el argumento bourdiano permite enmarcar aquellas reflexiones en el marco más general de la permanencia de las relaciones de dominación.

Aunque predominante, la interpretación del éxito anteriormente descripta convive con una noción más convencional, la cual supone algún tipo de reconocimiento externo (social o familiar):

"Yo creo que tengo éxito, creo que tengo reconocimiento...."

"Eso fue una cosa que siempre estuvo en mi cabeza.....que yo quería trabajar, que yo quería tener brillo propio. Y yo

Para Judy Wajcman (1996) el simbolismo dominante en las organizaciones está embebido de imágenes de masculinidad, el éxito organizacional se presenta como agresivo, competitivo e inflexible, todas características de un líder poderoso. El trabajo gerencial es conceptualizado como envolviendo constante acción, la imagen es la de un fire-fighter propinando golpes con una prisa constante, haciendo más que pensando. De esta manera, la construcción social de los puestos gerenciales (y consecuentemente del éxito) está relacionada con la imagen de la competencia ligada a las cualidades masculinas. Un análisis similar se desprende de la investigación de Merriel-Sandes y Kolb (2001). Para las autoras la autonomía, la disciplina y el control emocional constituyen las imágenes centrales del éxito a nivel organizacional. 
creo que conseguí en mi vida eso. Yo creo que tengo un respeto profesional, reconocimiento."

"Siento que tuve éxito, sí, por el hecho de conseguir trabajar en una empresa tan bien conceptuada como N.N."

"De mi lado, todos mis hermanos tienen el mayor orgullo...."

Es particularmente interesante resaltar que en las mujeres mayores de 40 años la idea de éxito profesional -como satisfacción personal o reconocimiento externo- es indisociable de la realización en el espacio doméstico. Esto puede ser aprehendido formando parte de la doble inserción profesional y doméstica, pero también como una noción ampliada de la realización personal que incluye dimensiones diversas (profesionales, afectivas y espirituales):

"Entonces, yo creo que la gran virtud,... la gran sabiduría que tenemos que tener es saber coordinar las dos cosas, ¿no es? Es decir, tenés el lado profesional, el lado serio, el lado de la satisfacción profesional, pero no podés olvidar que sos mujer, ¿no es? Este lado también tiene que ser preservado. Tanto la relación profesional como nuestras relaciones personales. Yo creo que una cosa es complementaria de la otra, ¿sabés? Yo creo que no viviría solamente con la satisfacción del trabajo o sólo con el casamiento y la relación con otras personas. Yo creo que el trabajo es parte de mi vida. Yo no viviría sin mi trabajo."

Se puede apreciar que las nociones de éxito contenidas en las prácticas de las mujeres ejecutivas son diversas y heterogéneas. Ellas denotan la mayor parte de las veces prácticas con un sentido diferente de las masculinas, pero, fundamentalmente, prácticas con un marcado grado de independencia en lo que se refiere a los criterios de éxito socialmente aceptados. Este tipo de aproximación, al apartarnos de las tradicionales interpretaciones del "temor al éxito", nos permite un mayor margen analítico para comenzar a pensar en la construcción de una idea de éxito anclada en valores diferentes de la competencia, de la racionalidad instrumental, del utilitarismo y de la jerarquía.

\section{A manera de cierre}

Es imposible transitar el camino analítico de las transformaciones en las relaciones de género sin remitirnos rápidamente a los grandes dilemas de la sociología. Permanencia vs. cambio, estructura vs. acción, acción individual vs. acción colectiva se imponen en el camino recorrido, fijando al mismo tiempo sus límites.

Transitar este camino desde el lugar de las representaciones construidas por las mujeres ejecutivas en torno a la discriminación y al éxito ofrece un fructífero campo de análisis, campo en el cual estos dilemas se expresan con una fuerza singular.

A pesar de no ser completamente homogéneas, las representaciones sobre el éxito y el logro translucen prácticas que tienden a distanciarse de los criterios dominantes y expanden dentro del grupo estudiado valores diferentes a la jerarquía, al utilitarismo y a la competencia. Estos valores se encuentran fundamentalmente anclados en el fortalecimiento de la auto-estima y de la realización personal y tienen como condición básica para su desarrollo el reconocimiento personal y externo de la idea de 
"competencia profesional", entendida esta como una capacidad técnica, una calificación profesional adquirida en el ámbito educativo y laboral.

Sin embargo, las representaciones y las prácticas innovadoras en este aspecto conviven con representaciones de la discriminación que actúan minimizando la existencia de las desventajas de género.

No obstante, el sujeto mujer ser fragmentado y heterogéneo es posible pensar, para el caso de las mujeres ejecutivas brasileñas, en un perfil común, o mejor en un perfil con algunos trazos en común y en el surgimiento de una primera etapa en la construcción de nuevas trayectorias profesionales. Trayectorias constituidas por una configuración específica estrechamente relacionada con una fuerte inversión en educación y con un compromiso inédito con el vínculo de trabajo.

Sin embargo, los elementos innovadores en la construcción de las trayectorias profesionales de las mujeres ejecutivas no convive con la noción de formar parte de un colectivo de mujeres, ni contienen la perspectiva de una acción política mayor que pueda potenciar la situación de cambio y hacerla extensiva a todos los segmentos socio-ocupacionales.

De esta manera, una mirada de la realidad desde la óptica anteriormente descripta arroja sombra sobre los mecanismos institucionales que reproducen y refuerzan las desventajas de género, pero fundamentalmente cierra puertas al trabajo colectivo de construcción de una política que promueva y potencie transformaciones sustantivas en las formas en que se construyen las relaciones entre los sexos.

\section{Referencias Bibliográficas}

Arango, Luz Gabriela (1998), "Familia, Trabajo e Identidad de Género. Analogías y Contrastes entre dos Categorías Socio-Profesionales en América Latina" en Abramo, Laís, Abreu, Alice Rangel de Paiva (org), Gênero e Trabalho na Sociologia Latino-americana (ALAST). São Paulo, Rio de Janeiro.

Bourdieu, Pierre (2000), La Dominación Masculina. Anagrama. Barcelona.

Bozon, Michel (1995), "Amor, Sexualidade e Relações Sociais de Sexo na França Contemporânea". Estudos Feministas, ano 3, n. 1. IFCS/UFRJ.

Cappellin, Paola (1996), "Ações Afirmativas: uma Estratégia para Corrigir as Desigualdades entre Homens e Mulheres" en Ligocki, Malô Simões Lopes, Libardoni, Marlene. Discriminação Positiva-Ações Afirmativas: em Busca da Igualdade. CFEMEA/ELAS. São Paulo-Brasil.

García de Fanelli, Ana (1991), "El Empleo Femenino en la Argentina: de la Modernización de los '60 a la Crisis de los '80" en Desarrollo Económico. Vol. 31, N 123, octubre-diciembre.

Heller, Lidia (2002), Mujeres Ejecutivas en Argentina. Nuevas Voces de Liderazgo. Disponible en Internet vía: www.modemmujer.org. Consultado diciembre de 2002.

Heller, Lidia (2003), Mujeres Ejecutivas en Argentina. Una Radiografía para Saber cómo Somos. Disponible en Internet via: www.mujeressin frontera.com. Consultado diciembre de 2003.

InfoPYME (2001), El Libre Comercio y las Mujeres en las Esferas de Negocio en América. Teresa Lozano Long Institute of Latin America Studies, University of texas al Austin. Octubre, vol. 4. 
Kaa, Van de Dick J. (1987, March), "Europe's Second Transition". Population Bulletin 42 (1). New York, United Nations.

Laufer, Jacqueline (1986), “L’Égalité Professionelle: du Principe à la Mise en Oeuvre" en Aubert, Nicole, Enriquez, Eugène, Gaulejac, Vincent de. Le Sexe du Pouvoir. Femmes, Hommes et Pouvoirs dans les Organizations. Desclée de Brouwer. Paris.

Markus, Maria (1990), "Mujeres, Éxito y Sociedad Civil. Sumisión o Subversión del princípio de logro" en: Benhabib, Seyla, Cornella, Drucilla. Teoría Feminista y Teoría Crítica. Edicions Alfons el Magnànim, Generalitat Valenciana. Valencia-España.

Merriel-Sandes, Deborah, Kolb, Deborah.(2001), "Women as leaders: The paradox of success". Center for Gender in Organizations. Disponible en Internet via: www.simmons. edu.com. Consultado diciembre de 2003.

Puppin, Andréia (1994), "Mulheres em Cargos de Comando" en Bruschini, Cristina, Sorj, Bila (orgs.) Novos Olhares: Mulheres e Relações de Gênero no Brasil. São Paulo, Fundação Carlos Chagas, Editora Marco Zero.
Puppin, Andréia (1998), Do Lugar das Mulheres e das Mulheres Fora de Lugar Um Estudo das Relações de Gênero numa Empresa Petrolífera. Orientador: Luiz Eduardo Soares. Rio de Janeiro: IUPERJ. 198 p. Dissertação. (Doutorado em Ciências Humana: Sociologia).

Reygadas, Luis (1998), "Fábricas con Aroma de Mujer. Las Nuevas Culturas del Trabajo Vistas desde la Óptica de Género" en Abramo, Laís, Abreu, Alice Rangel de Paiva (org), Gênero e Trabalho na Sociologia Latino-americana. São Paulo, Rio de Janeiro, ALAST.

Santos, Selene (1982), "A Mulher de Formação Universitária em Algumas Empresas Estatais", en Bruschini, M.C., Rosemberg, F.(ed.) Trabalhadoras do Brasil. São Paulo, Fundação Carlos Chagas, Brasiliense.

Wajcman, Judy (1996), "Women and Men Managers" en Cropton, Rosemary, Gallie, Duncan, Purcell, Kete (eds.) Changing Forms of Employment. Organizations, Skills and Gender. New York, Routledge. 
Kaa, Van de Dick J. (1987, March), "Europe's Second Transition". Population Bulletin 42 (1). New York, United Nations.

Laufer, Jacqueline (1986), “L’Égalité Professionelle: du Principe à la Mise en Oeuvre" en Aubert, Nicole, Enriquez, Eugène, Gaulejac, Vincent de. Le Sexe du Pouvoir. Femmes, Hommes et Pouvoirs dans les Organizations. Desclée de Brouwer. Paris.

Markus, Maria (1990), "Mujeres, Éxito y Sociedad Civil. Sumisión o Subversión del princípio de logro" en: Benhabib, Seyla, Cornella, Drucilla. Teoría Feminista y Teoría Crítica. Edicions Alfons el Magnànim, Generalitat Valenciana. Valencia-España.

Merriel-Sandes, Deborah, Kolb, Deborah.(2001), "Women as leaders: The paradox of success". Center for Gender in Organizations. Disponible en Internet via: www.simmons. edu.com. Consultado diciembre de 2003.

Puppin, Andréia (1994), "Mulheres em Cargos de Comando" en Bruschini, Cristina, Sorj, Bila (orgs.) Novos Olhares: Mulheres e Relações de Gênero no Brasil. São Paulo, Fundação Carlos Chagas, Editora Marco Zero.
Puppin, Andréia (1998), Do Lugar das Mulheres e das Mulheres Fora de Lugar Um Estudo das Relações de Gênero numa Empresa Petrolífera. Orientador: Luiz Eduardo Soares. Rio de Janeiro: IUPERJ. 198 p. Dissertação. (Doutorado em Ciências Humana: Sociologia).

Reygadas, Luis (1998), "Fábricas con Aroma de Mujer. Las Nuevas Culturas del Trabajo Vistas desde la Óptica de Género" en Abramo, Laís, Abreu, Alice Rangel de Paiva (org), Gênero e Trabalho na Sociologia Latino-americana. São Paulo, Rio de Janeiro, ALAST.

Santos, Selene (1982), "A Mulher de Formação Universitária em Algumas Empresas Estatais", en Bruschini, M.C., Rosemberg, F.(ed.) Trabalhadoras do Brasil. São Paulo, Fundação Carlos Chagas, Brasiliense.

Wajcman, Judy (1996), "Women and Men Managers" en Cropton, Rosemary, Gallie, Duncan, Purcell, Kete (eds.) Changing Forms of Employment. Organizations, Skills and Gender. New York, Routledge. 